\title{
THE GROWTH OF ICE CRYSTALS IN WATER
}

\author{
By Kiyoshi Arakawa \\ (Faculty of Science, Hokkaidô University, Sapporo, Japan)
}

\begin{abstract}
Using the shadow-photograph method the processes of growth of disc crystals and of ice dendrites formed in water are studied. A mechanism of dendritic crystal growth is suggested.

Zusammenfassung. Es wurden das Wachsen von Scheibenkristallen und die Bildung von Eisdendriten unter Anwendung der Schatten rissmethode werden studiert. Eine Theorie für das dendritische Kristallwachstum wird vorgeschlagen.
\end{abstract}

\section{INTRODUCTION}

Various physical properties of ice and water have been studied by scientists for a long time, but a more detailed knowledge of the freezing process is necessary for the better understanding of these problems. 'The best work on the freezing of water has been done by Altberg1 in his studies of anchor ice, as observed in the freezing of various rivers in the U.S.S.R. In this paper some qualitative results of observations on freezing phenomena are reported.

The experiments were carried out in a cold chamber at the Institute of Low Temperature Science annexed to the University.

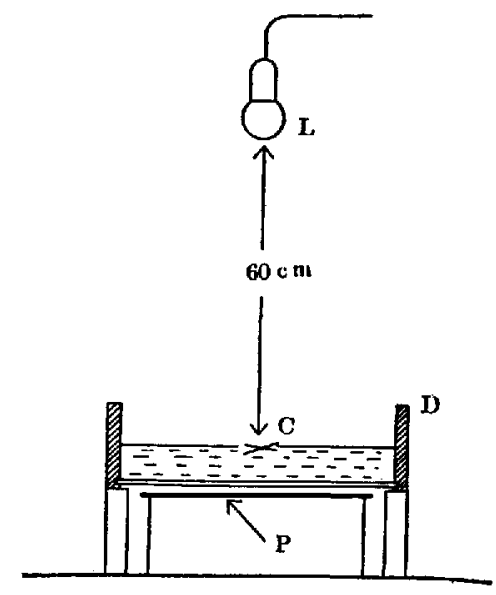

Fig. I

\section{Shadow-Photograph Method}

The macroscopic freezing processes occurring on a comparatively large area of water surface are the most suited for the study by the photographic method. ${ }^{2}$ The apparatus used is shown schematically in Fig. I (above).

An ice crystal $C$ formed on the surface of water in a shallow vessel $D$ is illuminated from above by a point light from source $L$. The bottom of this vessel is made of glass. Thus a shadow of the ice crystal is projected through it onto photographic paper $P$, which is placed just beneath the bottom of the vessel. By giving a suitable exposure with an electric switch, a clear photograph of the ice crystal can be obtained. It is also possible to observe directly the shadow of the crystal projected onto a sheet of white paper placed at $P$. In this case, the white paper should be placed a few centimetres away from the bottom of the glass in order to get the most contrasting image: 


\section{The Disc Crystal}

Imai ${ }^{3}$ has reported that disc crystals are formed which are optically uniaxial with their principal axis perpendicular to the surface of the disc. The present author's observations under a polarizing microscope also agree with that report. Further, such a crystal is probably optically positive. These properties are the same as have previously been obtained for bulk ice. ${ }^{4} \mathrm{~A}$ series of shadow photographs, Figs. 2-9 (p. 465), show successive stages of the growth of a disc crystal into a dendrite. Fig. 2 shows the state just before the formation of a "notched" crystal. A black circle appears at a certain distance from the periphery of the crystal, and gradually shrinks inwards as shown in Fig. 3. In a short time it disappears and the crystal takes a notched or incised form. The black circle indicates gradual changes in the surface at the edge of the crystal. Six main branches radiate prominently in a stellar form, and then a beautiful dendrite attains its perfect shape similar to that of a stellar crystal of snow. Figs. Io and II (p. 466) are ordinary photomicrographs of another crystal in the early stage of dendrite formation. There is some difference in appearance between the pictures taken by the two photographic methods.

\section{DENDRITE GROWTH}

Ice crystals on the water surface are nearly dendritic in the later stages of growth. Fig. I2 (p. 467) shows various forms of dendrites formed on the water surface. On a wide water surface, dendrites often grow into a kind of criss-cross pattern as shown in Fig. I3 (p. 467). The process of freezing as observed on a glass plate placed at the bottom of the vessel shows one more interesting phenomenon which suggests a certain mechanism for dendritic growth. Photomicrographs, Figs. $1_{4}$ and $I_{5}$ (p. 466 ), show the early stages of the dendritic growth in this case. Fig. 14 shows five needle-like crystals grown in slightly supercooled water; they have flat surfaces in their early stages, but gradually many transverse furrows are produced on the flat surfaces. Then new branches develop from the points intermediate between those furrows. The primary branches have an optic axis different from that of the mother needles. In Fig. 14, after the mother crystal had grown out into a continuous wide front, the primary branching occurred a little more sparsely between furrows, and grew into fan-shaped crystals at a slight inclination to the mother crystal.

\section{Discussion}

It may now be asked why an ice crystal grows into a disc form. The answer is to be found in the mechanism of the dendritic growth of the crystal. The consistent behaviour shown in Fig. 13 suggests that internal conditions are more important than external ones. The growth of the furrows on the mother crystal suggests the existence of a mechanical stress in the crystal. Then imperfections caused by this stress would play the part of effective nuclei for the successive branching.

In conclusion, the author wishes to express his indebtedness to the Educational Ministry of Japan for financial assistance in making this research.

MS. received 30 December 1953

\section{R E F E R E N C E S}

I. Altberg, W. J. Twenty years of work in the domain of underwater ice formation (1915-35). Union Internationale de Géodésie et de Géophysique, Association Internationale d'Hydrologie Scientifique. Sixième Assemblée Général à Edimbourg, 1936, Bulletin No. 23, Riga [1938], p. 373-407.

2. Arakawa, K., and Higuchi, K. Studies on the freezing of water (I). Fournal of the Faculty of Science, Hokkaidô University, Series 2 (Physics), Vol. 4, No. 3, I952, p. $201 \multimap 08$.

3. Imai, I. On the freezing of water. Seppyo (Joumal of the Japanese Society of Snow and Ice), Vol. I I, I949, p. 10 (in Japanese).

4. Smithsonian Physical Tables. Eighth Revised Edition, 1933, p. 365. International Critical Tables, Vol. 7, 1930, p. 17.

Comments on this paper by Dr. J. W. Glen are printed on p. $483-E d$. 


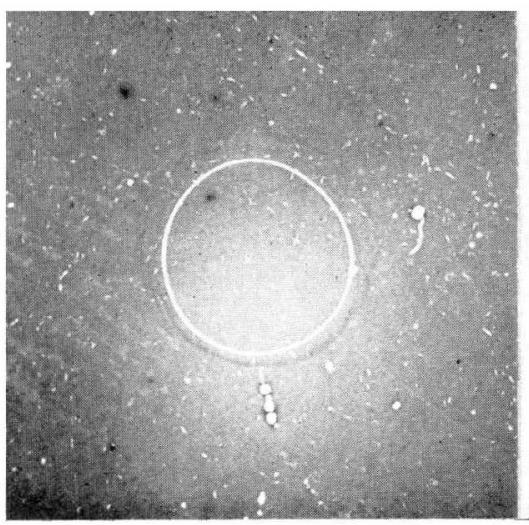

Fig. 2

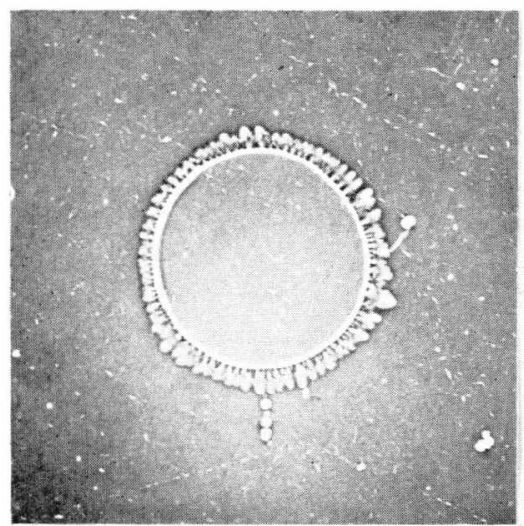

Fig. 5

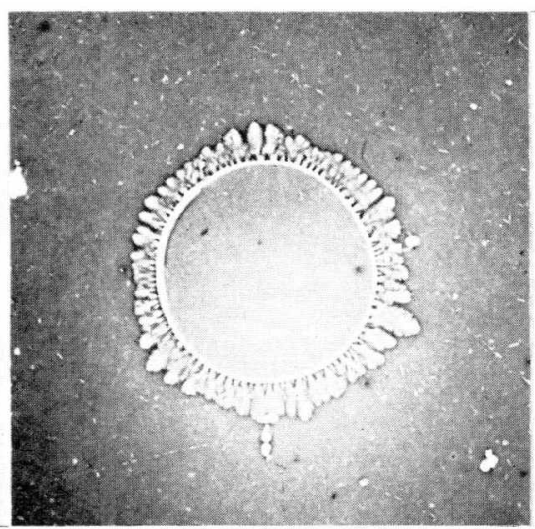

Fig. 6

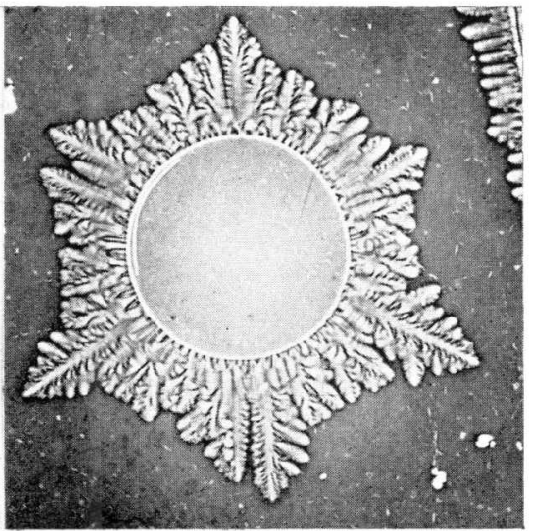

Fig. 9

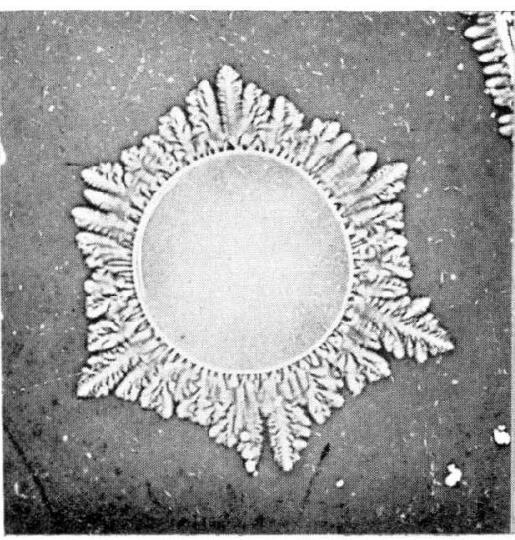

Fig. 8

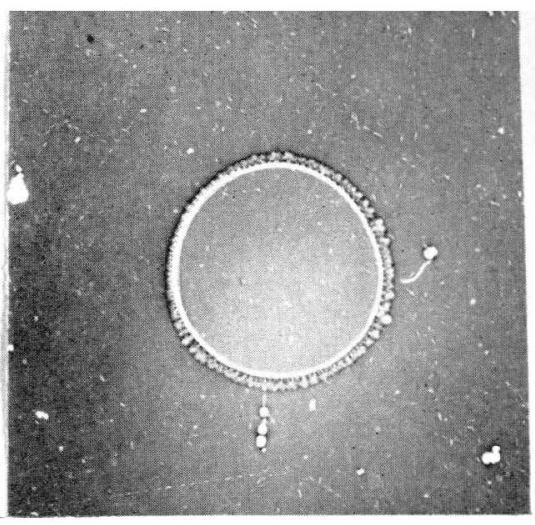

Fig. 4

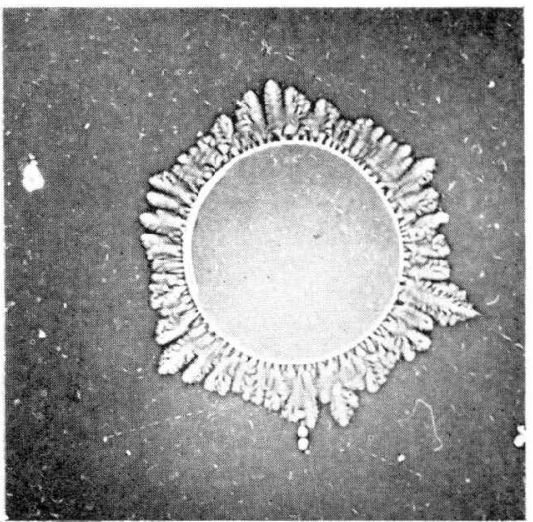

Fig. 7
Successive stages of dendritic growth. Photographs taken at intervals of 30 seconds 

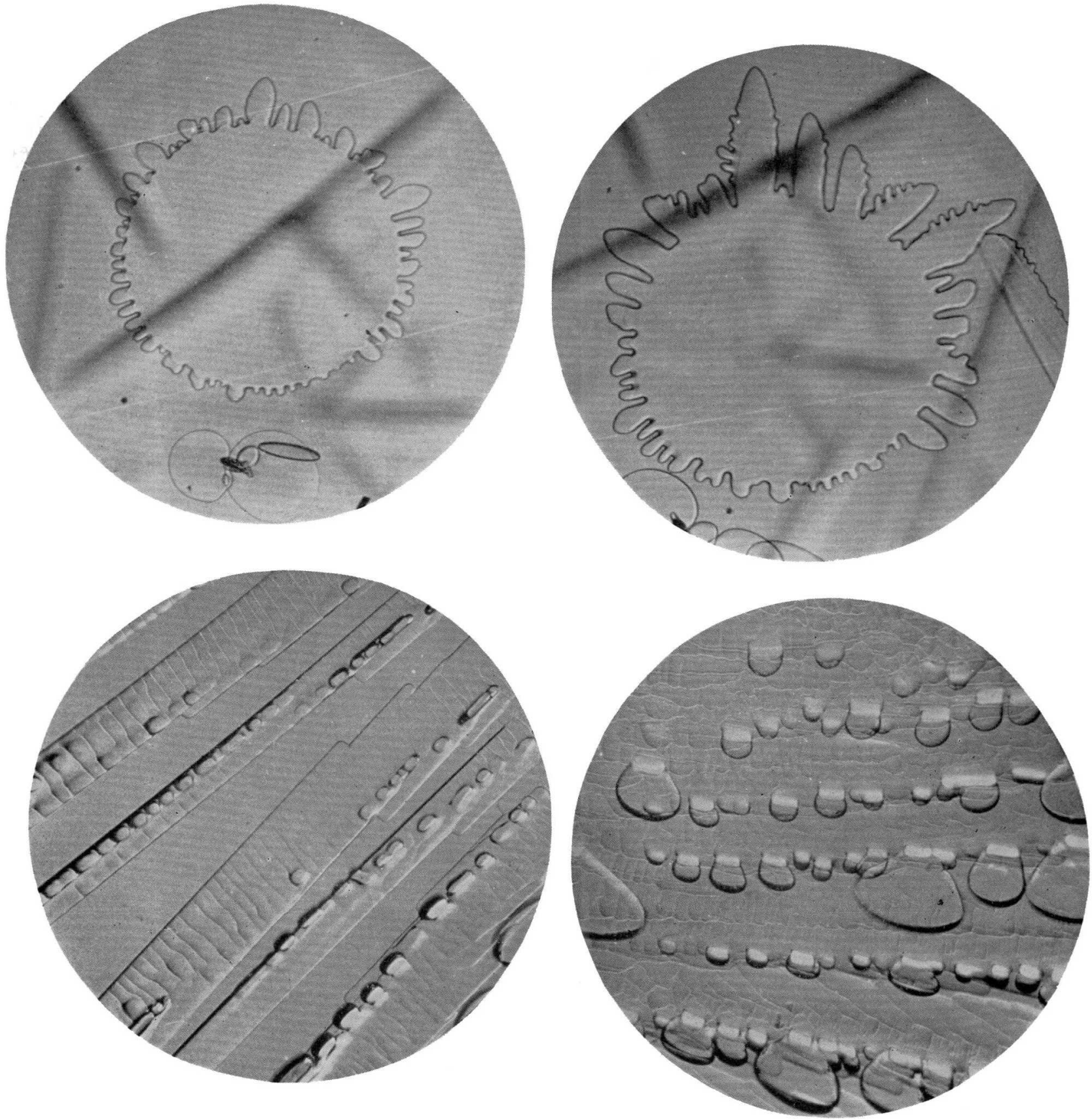

Fig. 10 (top left). Dendritic growth of a disc crystal in zater. $\times 22$

Fig. II (top right). Growth of secondary branches one minute after Fig. TO. $\times 22$

Fig. I4 (bottom left). Needle-like crystals with furrows on their surfaces. $\times 22$

Fig. I5 (bottom right). Fan-shaped crystals grown from the mother crystal. $\times 22$ 

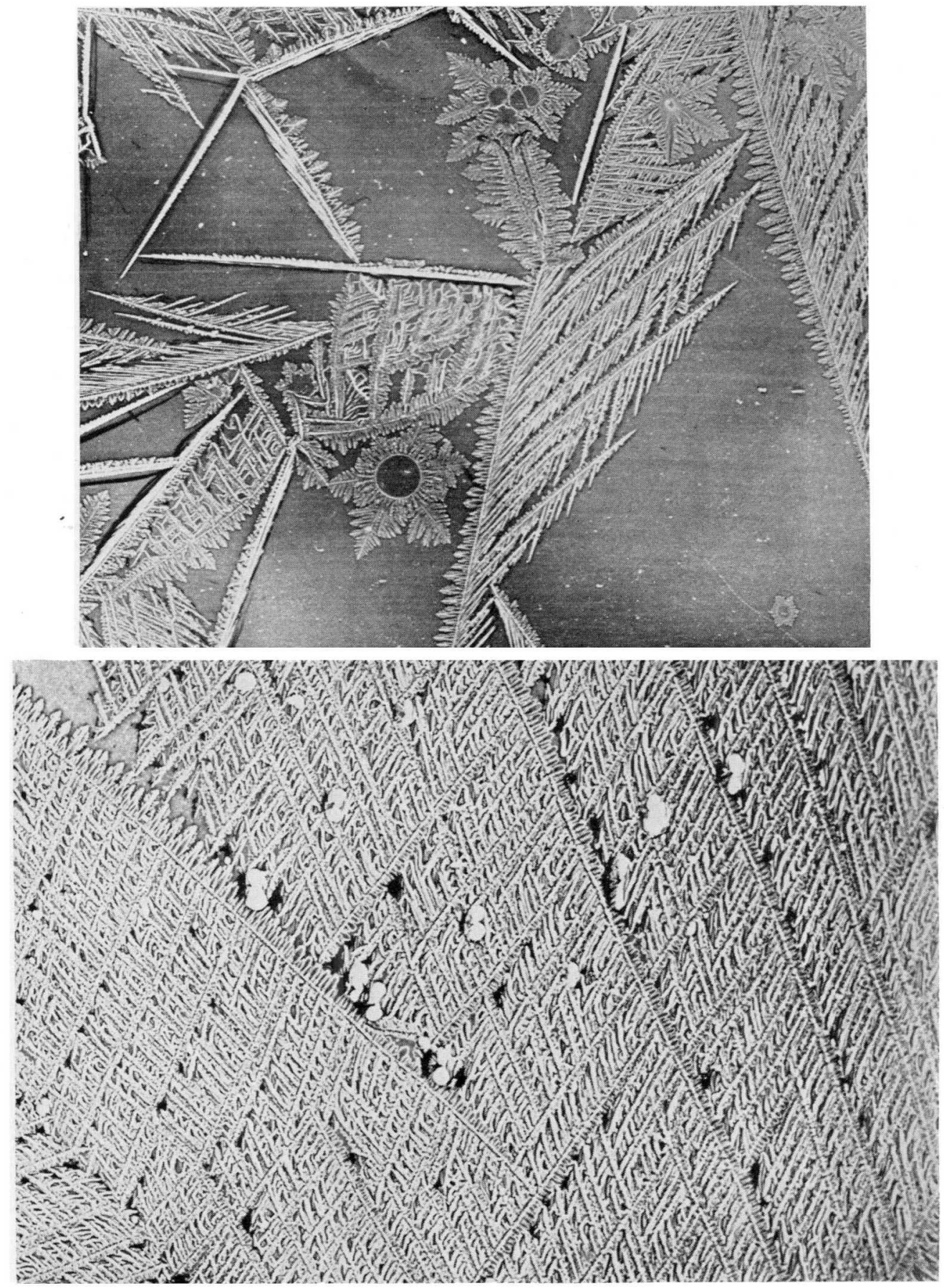

Fig. T2 (above). Shadow photograph of various forms of dendrites growing on auter surface. Natural size

Fig. ${ }_{3}$ (below). Dendrite grown into chequered or criss-cross form. $\times 1.5$ 

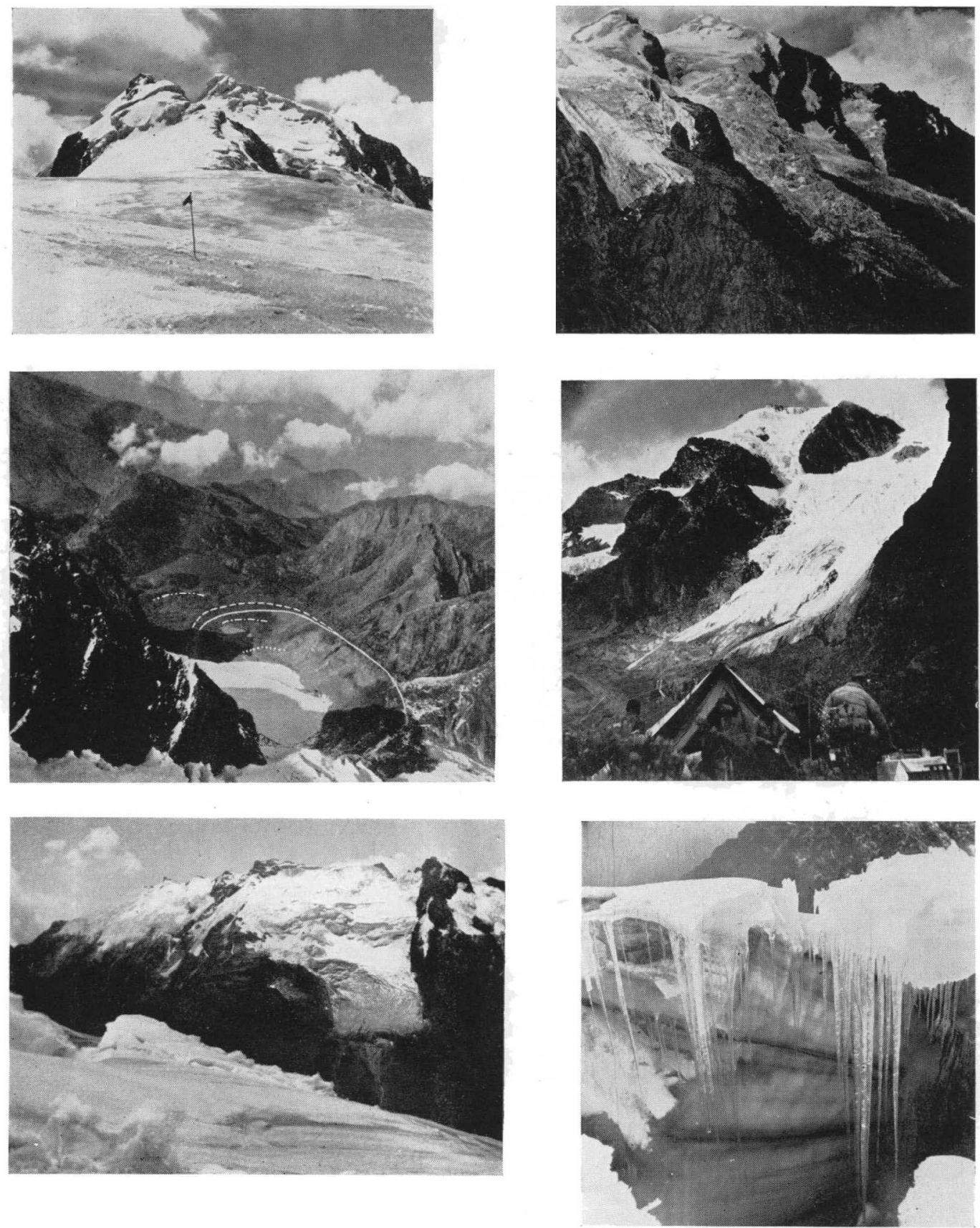

Fig. 2 (top left). Margherita (5Ir9 m.), the highest peak of Ruzcenzori. In the foreground, the Stanley Platean

Fig. + (centre left). The melt area of the Stanley Glacier in 19.32. In 1952 the front part of the glacier acas hidden by the cliff in the foreground. Successive achite lines indicate from the left: the last frontal moraine built up by the Pleistocene glacier probably before this thawed completely; the Late-glacial moraine; the maximum post-glacial extension of the recent glacier tongue; the outermost but one of the recent terminal moraines; the position of the glacier front in about $I 900$

Photograph by the Belgian Ruzvenzori Expedition $1932^{\circ}$

Fig. $5 a$ (bottom left). Mt. Speke from the west

Fig. $5 b$ (top right). The eastern glacier tongues of the Stanley Plateau. Margherita in the background

Fig. 6 (centre right). The western Stanley Glacier from Camp Lac Gris (4300 m.). Below the ice a light-coloured zone is seen in which no lichens are yet macroscopically visible; its outer boundary marks the position of the glacier about I930

Fig. 9 (bottom right). Crevasse with two well-marked dirt bands representing $\mathcal{Y} u n e-\mathcal{F} u l y$ ablation periods. The fin between them is one year's accumulation surplus. Fist below the upper dirt band is one less distinctly marked which represents the comparatively weak ablation period probably occurring in Fanuary and February 